\title{
Статистика интенсивности в случайном волоконном лазере
}

\author{
С.С. Вергелес ${ }^{1,2}, \underline{\text { Л.Л. Огородников }}{ }^{1,3,4, *}$ \\ ${ }^{1}$ Институт теоретической физики им. Л.Д. Ландау РАН, Черноголовка, Россия \\ ${ }^{2}$ Национальный исследовательский университет Высшая Школа Экономики ${ }^{3}$ Московский физико- \\ технический институт (ГУ) \\ ${ }^{4}$ Сколковский институт науки и технологий \\ "E-mail: noel95@mail.ru
}

DOI:10.31868/RFL2018.97

В последнее время большой интерес вызывают исследования в активно развивающейся области физики, связанной со случайными волоконными лазерами. Их создание и развитие имеют большое значение для различных телекоммуникационных средств связи и распределенных сенсорных систем [1-4].

В [5] построена волновая кинетическая теория для активных циклических слабонелинейных волновых систем, которая может быть использована для описания работы случайного волоконного лазера. В частности, были установлены спектры излучения при разных мощностях порога генерации, зависимость интенсивности излучения от частоты и зависимость ширины спектра от выходной мощности, которые хорошо описывают имеющиеся экспериментальные результаты [5].

Одним из неисследованных вопросов, связанных со случайным волоконным лазером, является статистика излучения данного лазера. Такие процессы, как спонтанное излучение, а также взаимодействие различных гармоник, приводят к формированию гауссовой статистики амплитуды, то есть релеевской статистике интенсивности. Однако, экспеиментально [6] в подобных системах наблюдаются сильные флуктуации выходного сигнала. Подобные флуктуации могут возникать за счёт Керровской нелинейности, поэтому функция распределения выходной интенсивности может иметь отличие от релеевского вида.

Целью данной работы является нахождение статистики излучения. Поставленная задача решается путем вычисления корреляционных моментов интенсивности высших порядков и построения по ним функции распределения.

В данной работе производится вычисление коррелятора четвертого порядка с использованием диаграммной техники Уайльда в первом и во втором порядке по теории возмущений по малому параметру нелинейности. В первом порядке по параметру нелинейности вычисляются моменты высших порядков и строится функция распределения интенсивности выходного излучения [6].

\section{Литература}

[1] S.K. Turitsyn et. al., Physics Reports 542, 133-193 (2014).

[2] Звелто О. “Принципы лазеров”, 4-е изд., СПб.: Издательство «Лань», 2008.

[3] S.K. Turitsyn et. al. Nature Photonics 4, 231-235 (2010).

[4] D.S. Wiersma, Nature Physics 4, 359-367 (2008).

[5] D.V. Churkin et. al., Nature Communications, 2 (2015).

[6] L.L. Ogorodnikov, S.S. Vergeles Opt. Lett, 43, 651-654 (2018). 